\title{
Studying the interaction of magainin 2 and cecropin A with E. coli bacterial cells using Circular Dichroism
}

Concetta Avitabile1 ${ }^{1}$, Luca Domenico D’Andrea ${ }^{1}$, Alessandra Romanelli ${ }^{1,2}$

${ }^{1}$ Institute of Biostructure and Bioimaging CNR, via Mezzocannnone 16, 80134 Naples

${ }^{2}$ Department of Pharmacy, University of Naples “Federico II”, via Mezzocannnone 16, 80134 Naples

\section{Summary}

The potential of antimicrobial peptides (AMPs) as an effective therapeutic alternative to classic and current antibiotics has encouraged studies to understand how they interact with the bacterial membrane. Here we describe how to detect, by Circular Dichroism (CD), the secondary structures of two antimicrobial peptides, Magainin2 and Cecropin A, in the presence of E.coli bacterial cells.

Key words: antimicrobial peptides, Circular Dichroism, E.coli cells.

\section{Introduction}

The comprehension of the mechanism by which antimicrobial peptides (AMP) kill bacteria requires a deep characterization of the interactions of such peptides with bacterial cells. A limited number of studies reported in the literature is focused on cell-peptide interactions, while the vast majority of investigations is aimed at the characterization of the interaction of AMPs with lipid mixtures or with the lipopolysaccharide (LPS), considered as a model systems for the bacterial outer membrane(1-5). Urged by the need to develop methods to explore the structure of peptides when bound to bacterial cells, we have set up a protocol to determine 
the secondary structure of peptides in the presence of E.coli cells by Circular Dichroism (CD). The protocol has been successfully applied so far to the study of peptides of different length, including cecropin A, magainin 2 and peptides belonging to the temporin family, such as the temporin B and its analogue TBKK_G6A(2, 3). Interestingly, the folding of peptides upon interaction with E.coli cells occurs only when the peptides are active against E.coli, while folding of peptides in the presence of E.coli lipopolysaccharide (LPS) seems to be independent on antimicrobial activity. In addition, we have recently reported the three-dimensional structure of the antimicrobial peptide TBKK_G6A either in the presence of E.coli lipopolysaccharide (LPS) and in the presence of E.coli cells(3, 6). The two structures are different, further confirming that all the components of the bacterial leaflet, including lipid A, proteins and LPS, are required for the specific peptide-cell recognition .

The case described refers to two natural peptides, Magainin 2 and Cecropin A, both cationic peptides, active against gram-positive and gram - negative bacteria. Cecropin A and Magainin 2 are known to be random coils in buffer and fold into helices upon interaction with LPS, detergents or vesicles $(7,8)$. Interestingly, folding into helices is also observed in the presence of E.coli cells, and the appearance of the spectrum is slightly different from that obtained in the presence of LPS(2). The protocol can be applied to analyze the secondary structure of other peptides with E.coli cells; it is worth highlighting that the concentration of the peptide needs to be optimized every time, depending on the length of the peptide.

\section{Materials}


Prepare all solutions using ultrapure water; filter buffer solutions on $0.22 \mu \mathrm{m}$ filter and degas before use. Run CD experiments at $25^{\circ} \mathrm{C}$.

\subsection{Cell lines and culture}

1. BL21 (DE3) cells

2. LB medium: Tryptone, yeast extract, $\mathrm{NaCl}$

\subsection{Peptide solutions components}

1. Sodium phosphate buffer $10 \mathrm{mM}, \mathrm{pH} 7$

2. Liophilized pure Magainin II peptide

3. Liophilized pure Cecropin A peptide

\section{Methods}

\subsection{E.coli cells}

\subsubsection{LB medium (1L)}

1. Dissolve $10 \mathrm{~g}$ tryptone, $5 \mathrm{~g}$ yeast extract, and $10 \mathrm{~g} \mathrm{NaCl}$ in $950 \mathrm{~mL}$ deionized water. Adjust the $\mathrm{pH}$ of the medium to 7.0 using $1 \mathrm{~N} \mathrm{NaOH}$ and bring volume up to 1 liter. Autoclave on liquid cycle for $20 \mathrm{~min}$ at $15 \mathrm{psi}$. Allow solution to cool to $55^{\circ} \mathrm{C}$. Store at room temperature or $+4^{\circ} \mathrm{C}$.

\subsubsection{Cell culture}

1. Day 1 (Afternoon): Inoculate $5 \mathrm{~mL}$ of autoclaved $L B$ medium in a sterile falcon with a small aliquot of bacteria, withdrawn scratching an E.coli glycerol stock with a sterile pipette or toothpick. Set the falcon into the shaker at $37{ }^{\circ} \mathrm{C}$ temperature and $180 \mathrm{rpm}$ over night.

2. Day 2 (Morning): Refresh the bacterial culture, diluting $100 \mu \mathrm{l}$ of the overnight culture into $10 \mathrm{ml}$ of sterile LB medium and set the suspension into the shaker 
at $37{ }^{\circ} \mathrm{C}, 180 \mathrm{rpm}$. Monitor the cell growth by UV, measuring the absorbance of the suspension at $600 \mathrm{~nm}\left(\mathrm{OD}_{600}\right)$.

3. When the cell culture reaches the exponential phase $(0.6-0.8 \mathrm{OD}$ at $600 \mathrm{~nm})$, centrifuge the bacterial suspension for $5 \mathrm{~min}$ at $5,000 \mathrm{~g}$ in a refrigerated microcentrifuge at $4{ }^{\circ} \mathrm{C}$.

4. Discard the supernatant; resuspend the bacterial pellet in $10 \mathrm{~mL}$ of $10 \mathrm{mM}$ phosphate buffer $\mathrm{pH} 7$ and then centrifuge for $5 \mathrm{~min}$ at $5,000 \mathrm{~g}$ in a refrigerated microcentrifuge at $4^{\circ} \mathrm{C}$. (Note 1)

5. Repeat step 4. two more times.

6. Resuspend the bacterial pellet in $10 \mathrm{mM}$ phosphate buffer $\mathrm{pH} 7$, to have suspensions at the desired $\mathrm{OD}_{600}$.

\subsection{CD experiments}

\subsubsection{Scanning the conditions to detect secondary structure}

1. Dissolve lyophilized peptides in the minimum amount of ultragradient water (filtered to 0.2 micron) and estimate the concentration of the mother solutions by UV(9). Measure the absorbance at $280 \mathrm{~nm}$ for Cecropin A $\left(\varepsilon_{280}=5500 \mathrm{M}^{-1} \mathrm{~cm}^{-1}\right)$ and at $205 \mathrm{~nm}$ for Magainin $2\left(\varepsilon_{205}=94390 \mathrm{M}^{-1} \mathrm{~cm}^{-1}\right)$.

2. Record CD spectra for the peptides dissolved in buffer at a $5 \mu \mathrm{M}$ concentration in the 260-201 nm measurement range, with $100 \mathrm{~nm} / \mathrm{min}$ scanning speed, $1 \mathrm{~nm}$ bandwidth, $4 \mathrm{~s}$ response time and $1.0 \mathrm{~nm}$ data pitch.

3. To determine the optimal peptide+cell ratio start measuring $C D$ spectra for mixtures at different peptide and cell concentrations. Prepare a cell suspension 
at $0.06 \mathrm{OD}_{600}$. This may be obtained diluting a $1 \mathrm{OD}_{600}$ E.coli suspension in phosphate buffer $10 \mathrm{mM}, \mathrm{pH}$ 7. Run the blank using only cells in buffer. E.coli cells possess a characteristic signature. (Figure 1) (Note 2)

4. Soon after measure, in a different cuvette, the CD spectrum of the mixture cell + peptide. To start use a $5 \mu \mathrm{M}$ peptide concentration and $0.06 \mathrm{OD}_{600}$ cells. (Notes 3 and 4)

5. Record CD spectra for the peptide and the peptide + cell mixture at different times $(0,2,4,6 \mathrm{~h}) .($ Note 5$)$

6. Repeat steps 3 to 5 using suspensions prepared with different concentrations of cells $\left(\mathrm{OD}_{600}: 0.075,0.1,0.11,0.13\right)$ and peptides $(5$ and $10 \mu \mathrm{M})$.

7. Analyze spectra obtained subtracting the cell blank to the cell + peptide mixture and choose the best conditions for recording more experiments.

\subsubsection{Detect folding of peptides on cells}

1. Record CD spectra for the best peptide+ cells mixture, chosen after the analysis of the spectra obtained at different cell and peptide concentrations. Run measurements every 20 minutes for 2 hours, after 4 and 6 hours. For magainin II and cecropin A use E.coli cells at $0.1 \mathrm{OD}_{600}$ and $5 \mu \mathrm{M}$ peptide concentrations. Subtract the $C D$ spectrum of the cell to the corresponding $C D$ spectrum of the peptide + cell mixture. (Figure 2)

2. Repeat the experiment at least twice. Spectra obtained using different batches of cells are usually not perfectly superimposable, but the intensity and the position of the CD bands are reproducible. 
3. Plot the intensity of the CD signal at $222 \mathrm{~nm}$ of the subtracted spectra (spectra of the cells+peptide mixture - spectra of the cells) vs time. Use Prism or similar programs to calculate the error on each experimental point. This plot will help to understand how long it takes for your peptide to fold upon incubation with E.coli cells. (Figure 3)

The protocol described is optimized for peptides cecropin A and magainin 2. In our experience, the optimal cell density is always between 0.08 and $0.1 \mathrm{OD}_{600}$ and the optimal peptide concentration depends on the length of the peptide. Shorter peptides are best analyzed at higher concentrations(3).

\section{Notes}

1. Collect the solutions containing cells, cell supernatants or residual pellets in a falcon and add bleach to kill cells. Dispose the solutions following waste regulations.

2. Before running the experiments on cells + peptide mixtures, run CD spectra for the peptide and the cells separately and check the HT value. The purity of the buffer is pivotal for the success of the experiment. The HT value increases with cell concentration. Be careful when testing different cell concentrations.

3. Use the same batch of cells for the mixture peptide + cell and for the blank. The intensity of the signals, in fact, slightly changes with the batch of cells.

4. You will always work with two cuvettes, one for the blank, the other for the peptide + cell mixture. When you remove one cuvette (for example the cuvette with blank) from the spectrophotometer to run the other measurement (for 
example that on the cell + peptide mixture), keep always samples at $25^{\circ} \mathrm{C}$. If the temperature outside is not controlled, for example if it is too hot, your cell will dye very soon and results will hardly be reproducible.

5. At the end of each experiment the quartz cuvettes need to be carefully cleaned, as cells stick to the cuvette. Fill each cuvette with a 4 or $6 \mathrm{M}$ guanidinium solution, remove the solution after $2 / 3$ hours. Rinse the cuvette 10 times with ultrapure water, with ethanol and finally dry the cuvette by insufflating nitrogen.

\section{References}

1. Freire, J. M., Gaspar, D., de la Torre, B. G., Veiga, A. S., Andreu, D., and Castanho, M. A. (2015) Monitoring antibacterial permeabilization in real time using time-resolved flow cytometry. Biochim Biophys Acta 1848, 554-60.

2. Avitabile, C., D'Andrea, L. D., and Romanelli, A. (2014) Circular Dichroism studies on the interactions of antimicrobial peptides with bacterial cells. Sci Rep 4, 4293.

3. Malgieri, G., Avitabile, C., Palmieri, M., D'Andrea, L. D., Isernia, C., Romanelli, A., and Fattorusso, R. (2015) Structural basis of a temporin $1 b$ analogue antimicrobial activity against Gram negative bacteria determined by CD and NMR techniques in cellular environment. ACS Chem Biol 10, 965-9.

4. Rosenfeld, Y., Papo, N., and Shai, Y. (2006) Endotoxin (lipopolysaccharide) neutralization by innate immunity host-defense peptides. Peptide properties and plausible modes of action. J Biol Chem 281, 1636-43.

5. Gee, M. L., Burton, M., Grevis-James, A., Hossain, M. A., McArthur, S., Palombo, E. A., Wade, J. D., and Clayton, A. H. (2013) Imaging the action of antimicrobial peptides on living bacterial cells. Sci Rep 3, 1557. 
6. Avitabile, C., Netti, F., Orefice, G., Palmieri, M., Nocerino, N., Malgieri, G., D'Andrea, L. D., Capparelli, R., Fattorusso, R., and Romanelli, A. (2013) Design, structural and functional characterization of a Temporin-1b analog active against Gram-negative bacteria. Biochim Biophys Acta 1830, 3767-75.

7. Silvestro, L., and Axelsen, P. H. (2000) Membrane-induced folding of cecropin A. Biophys J 79, 1465-77.

8. Bechinger, B., Zasloff, M., and Opella, S. J. (1993) Structure and orientation of the antibiotic peptide magainin in membranes by solid-state nuclear magnetic resonance spectroscopy. Protein Sci 2, 2077-84.

9. Anthis, N. J., and Clore, G. M. (2013) Sequence-specific determination of protein and peptide concentrations by absorbance at $205 \mathrm{~nm}$. Protein Sci 22, 851-8. 


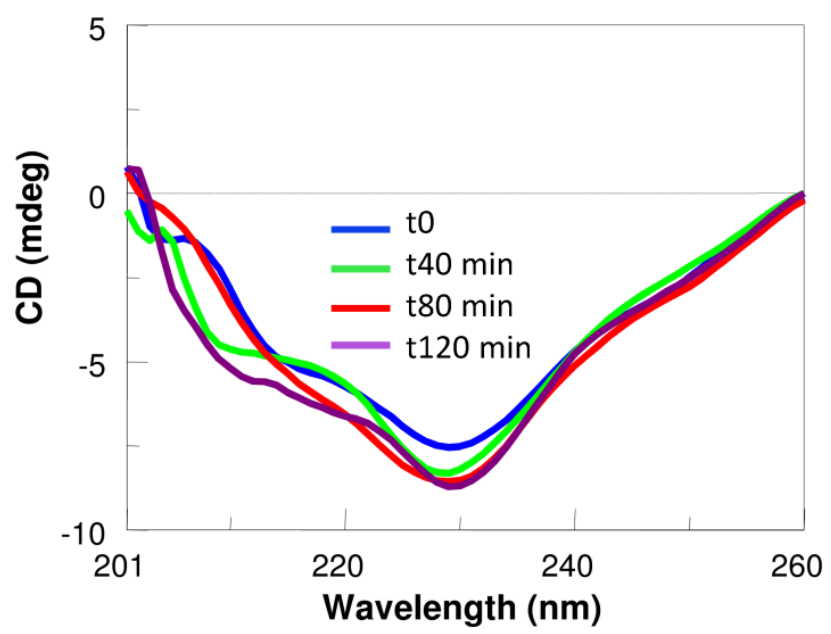

Figure 1. CD spectra of E.coli cells suspended in phosphate buffer pH 7 at different times (Panels reported are a reproduction of those published in ref 2 ).
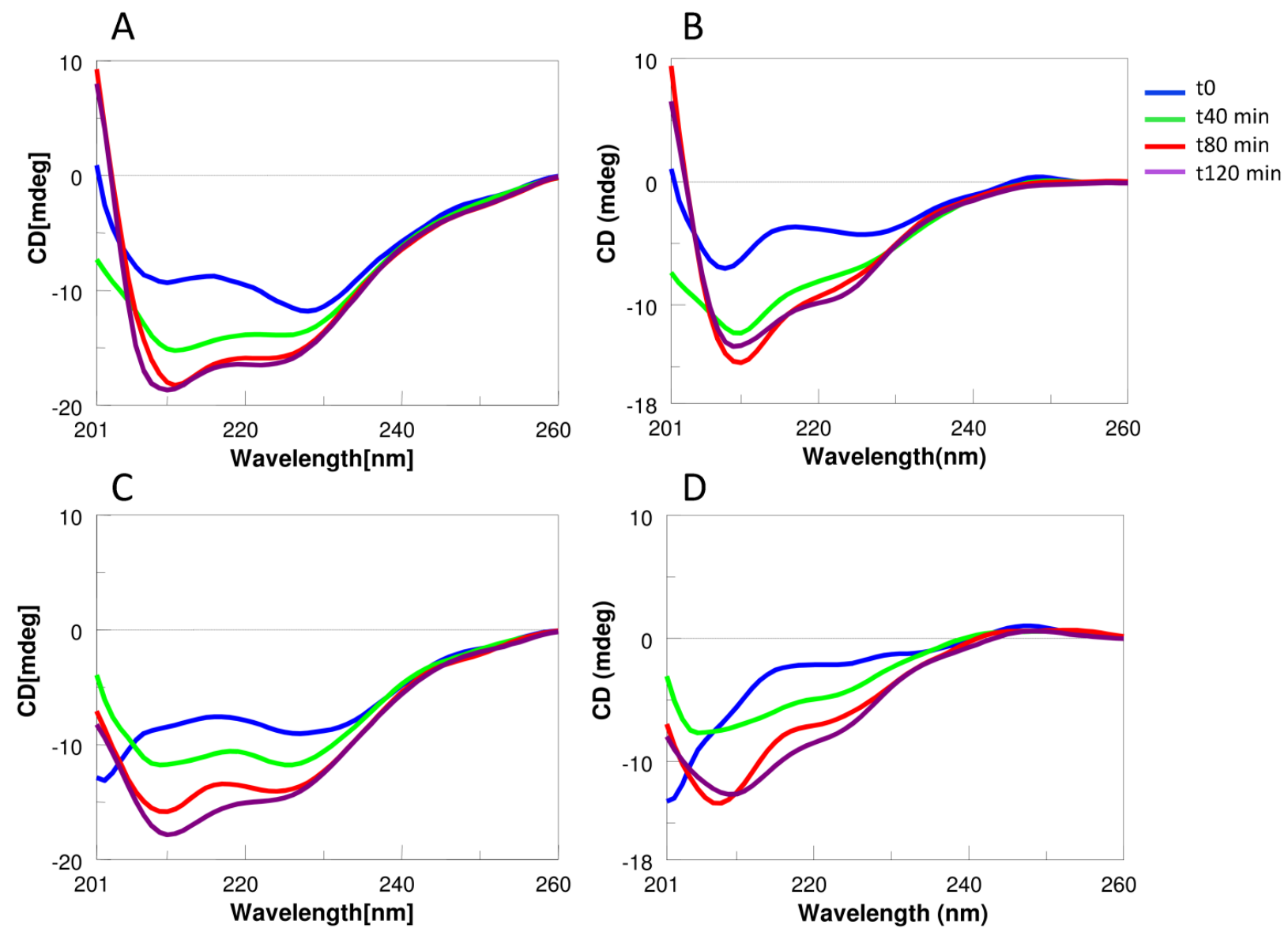
Figure 2. A, C: CD spectra of cell + peptide mixtures (A: magainin 2, C: cecropin A); B and D: CD spectra obtained after subtraction of the cell spectra to the cell + peptide mixture spectra (B: magainin II, D: cecropin A). (Panels reported are a reproduction of those published in ref 2)

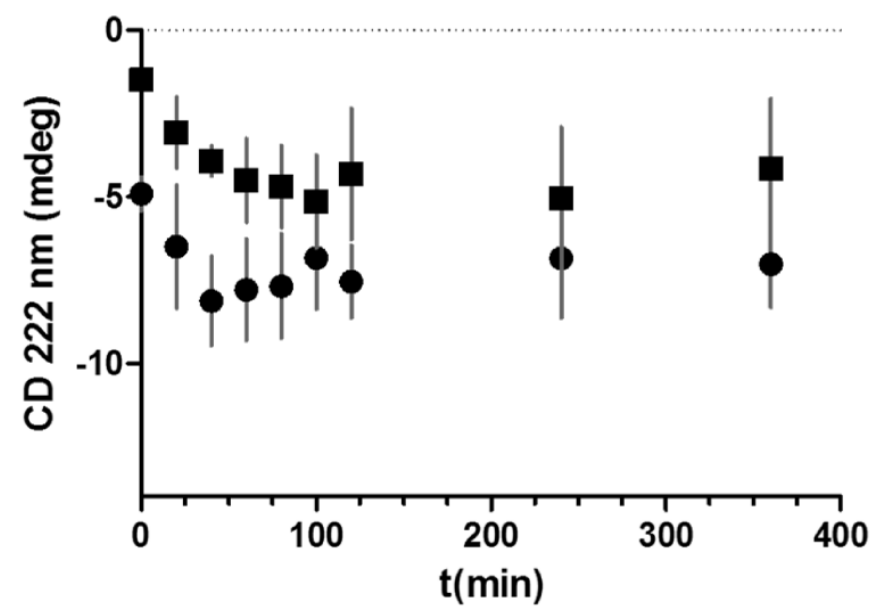

Figure 3. Plot of the CD signal intensity at $222 \mathrm{~nm}$ (as obtained from subtracted spectra) vs time for magainin II (circles) and cecropin A (squares). (The figure reported is a reproduction from ref 2 ) 